\title{
Calculation of Cd Content Settlement in a Circle of Coastal Waters
}

\author{
Dongfang Yang ${ }^{1}$, a, Haixia $\mathrm{Li}^{1}$, Longlei Zhang ${ }^{1}$, Qi Wang ${ }^{1}$, and Hong Zhu ${ }^{1}$ \\ ${ }^{1}$ Accountancy Shool, Xijing University, Xi'an 710123, China, \\ ${ }^{2}$ North China Sea Environmental Monitoring Center, SOA, Qingdao 266033, China,
}

\begin{abstract}
With the help of the data about $\mathrm{Cd}$ in the southeast and southwest waters of Jiaozhou bay and models of horizontal and vertical matter content variation proposed by the authors, horizontal loss amount and vertical diluted amount of $\mathrm{Cd}$ content in the surface layer and bottom layer are calculated, and the model block diagrams of horizontal and vertical variation of $\mathrm{Cd}$ content are determined. The calculation shows that in August, the absolutely horizontal loss amount of $\mathrm{Cd}$ content in the surface layer and bottom layer was $0.06-0.43 \mu \mathrm{g} / \mathrm{L}$, and the relatively horizontal loss amount of $\mathrm{Cd}$ content in the surface layer and bottom layer was $42.85-57.33 \%$. In the southeast and southwest waters of the bay, the absolutely verticaldiluted amount of $\mathrm{Cd}$ content in the surface layer and bottom layer was $0.24-0.61 \mu \mathrm{g} / \mathrm{L}$, and the relatively vertical diluted amount was $75.00-81.33 \%$. In the process of horizontal migration in August, in the surface waters, the main sea current carried $\mathrm{Cd}$ content through a circle of the nearshore waters in the bay, and there was almost no source of $\mathrm{Cd}$ content. Therefore, in the horizontal migration process of $\mathrm{Cd}$ content, after a long journey, the Cd content in the surface layer and bottom layer got a lot of losses. Specifically, the absolutely horizontal loss amount was $0.06-0.43 \mu \mathrm{g} / \mathrm{L}$, and the relatively horizontal loss amount was 42.85-57.33\%, which proved Dongfang Yang's migration law of matter content put forward by the authors. In the process of vertical migration in August, the Cd content transported by the main sea current was higher in the southeast waters of the bay, and the vertical diluted amount of Cd content in the surface layer and bottom layer was $81.33 \%$. The main sea current reached the waters of the southwest bay from the waters of the southeast bay through a circle of the nearshore waters in the bay. At this time, the Cd content transported by the main sea current was relatively low in the waters of the southwest bay, but the vertical diluted amount of $\mathrm{Cd}$ content in the surface layer and bottom layer was still very high, which was $75.00 \%$. It reveals that the vertical diluted amount of $\mathrm{Cd}$ content in the surface layer and bottom layer was very high in any water area, whether the Cd content is high or low.
\end{abstract}

\section{Introduction}

With the continuous discharge of a large amount of cadmium (Cd) to land and sea by human beings, the pollution of $\mathrm{Cd}$ content in the open waters and offshore waters is caused by the transportation of rivers and currents. Moreover, the river transports $\mathrm{Cd}$ content to the surface of seawater, and then the current migrates $\mathrm{Cd}$ content from one surface of waters to another. At the same time, in the migration, $\mathrm{Cd}$ content passed through the water body from the surface and settled to the seabed [1-6]. So, using the horizontal and vertical matter content change models proposed by the authors and the investigation data about Cd content in Jiaozhou Bay in August, 1992, the horizontal migration process and vertical sediment process of $\mathrm{Cd}$ content in Jiaozhou Bay waters were demonstrated, and the process and degree of water bodies pollution caused by $\mathrm{Cd}$ content transported by the main sea current were explained, which provides scientific basis for the study of vertical sedimentation and level of migration of $\mathrm{Cd}$ content in the surface and bottom waters.

\section{Waters, Materials and Methods}

\subsection{Natural Environment of Jiaozhou Bay}

Jiaozhou Bay is located in the south of Shandong Peninsula, and its geographical location is between $120^{\circ} 04^{\prime}-120^{\circ} 23^{\prime} \mathrm{E}$ and $35^{\circ} 58^{\prime}-36^{\circ} 18^{\prime} \mathrm{N}$. It is bounded by the connecting line between Tuan Island and Xuejia Island and communicates with the Yellow Sea, with an area of about $446 \mathrm{~km}^{2}$ and an average water depth of about $7 \mathrm{~m}$. It is a typically semi-enclosed bay. There are more than a dozen rivers flowing into the sea in Jiaozhou Bay, among which Dagu River and Yanghe River,and Haibo River, Licun River and Loushan River in Qingdao urban area are with large runoff and sediment concentration.All of them belong to seasonal rivers, and the hydrological characteristics have obvious seasonal changes $[7,8]$.

\subsection{Materials and Methods}

The investigation data about $\mathrm{Cd}$ in Jiaozhou Bay in August 1992 used in this study were provided by North China Sea Environmental Monitoring Center, SOA. In August, sampling was conducted at two sites in Jiaozhou Bay: sites 60 and 54 (Figure 1). And water samples were taken according to water depth (samples were taken from the surface layer and bottom layer when depth $>10 \mathrm{~m}$; only taken from the surface layer when depth $<10 \mathrm{~m}$ ). According to the national standard method which was included in the National Specification for Marine Monitoring (1991) [9], the $\mathrm{Cd}$ in Jiaozhou Bay was investigated. 


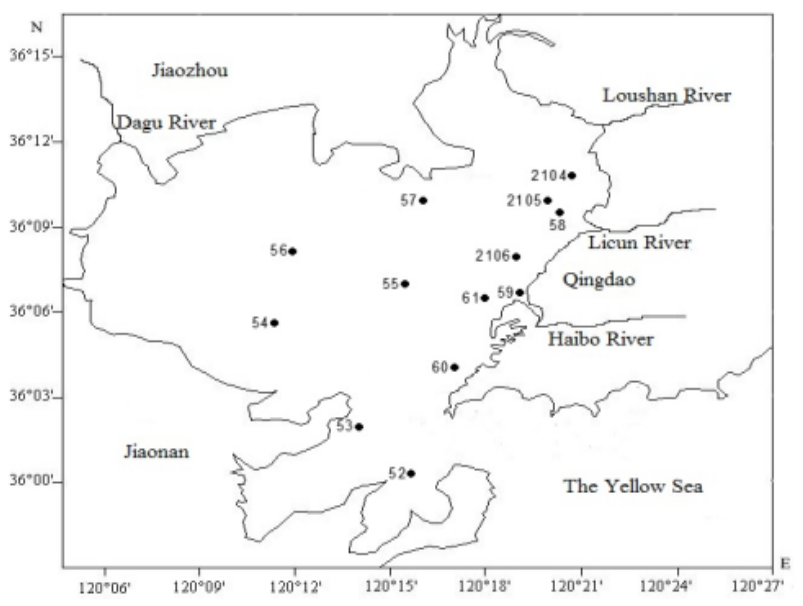

Figure.1. Investigation sites in Jiaozhou Bay

\section{Results}

\subsection{Waters from Southeast Bay to Southwest Bay}

In August, in the bay mouth waters of Jiaozhou Bay, the Cd content transported by the main sea current was $1.11 \mu \mathrm{g} / \mathrm{L}$. The main sea current entered Jiaozhou Bay with high content of Cd and reached the southeast of the bay. Then, the current circled the nearshore waters in the bay, reaching the southwest of the bay. Finally, it left Jiaozhou Bay (Figure 2).

In August, in the southeast waters of Jiaozhou Bay, the site is 60 . In the southwest waters of Jiaozhou Bay, the site is 54 .

In the surface waters, the main sea current carried $\mathrm{Cd}$ content of $1.11 \mu \mathrm{g} / \mathrm{L}$ into the bay waters, reaching site 60 with $\mathrm{Cd}$ content of $0.75 \mu \mathrm{g} / \mathrm{L}$. Then the current circled the nearshore waters in the bay, arriving at site 54 with $\mathrm{Cd}$ content of $0.32 \mu \mathrm{g} / \mathrm{L}$. In the bottom waters, the main sea current entered the bay waters through the southern waters of bay mouth and reached site 60 , with a Cd content of $0.14 \mu \mathrm{g} / \mathrm{L}$. Then the main sea current circled the nearshore waters of the bay, and reached site 54 with a $\mathrm{Cd}$ content of $0.08 \mu \mathrm{g} / \mathrm{L}$. Therefore, in the movement process of the bay current, the $\mathrm{Cd}$ content was constantly decreasing in both surface waters and bottom waters.

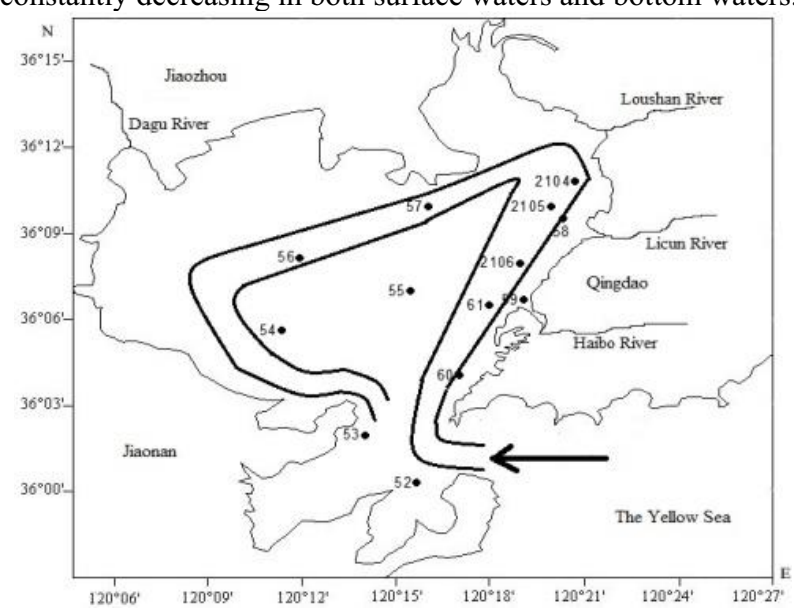

Figure.2. The flow path of the main sea current with high matter content in Jiaozhou Bay $(\mu \mathrm{g} / \mathrm{L})$

\subsection{Definitions of Horizontal Matter Content Change}

In Jiaozhou Bay, the bay current carried high matter content. And with the movement of the current, the matter content kept decreasing [10-13]. According to the definitions and formulae put forward by the authors, the horizontal loss amount, vertical diluted amount and vertical sediment amount of matter content are calculated. The horizontal loss amount of matter content can be divided into absolutely horizontal loss amount and relatively horizontal loss amount. The vertical diluted and sediment amounts of matter content can be divided into absolutely vertical diluted and sediment amounts and relatively vertical diluted and sediment amounts.

\subsection{Formulae for the Change of Horizontal Matter Content}

In the surface waters from southeastern bay to southwestern bay, it is assumed that the matter (M) content in southeast waters is $\mathrm{A}$ and that in southwest waters is B.

The absolutely horizontal loss amount of matter content is $\mathrm{D}>0$ and the relatively horizontal loss amount of matter content is $\mathrm{E}$ from the southeastern waters to the southwestern waters of the bay. When $\mathrm{D}<0$, it means that the absolutely horizontal loss amount of matter content is $-\mathrm{D}>0$ from the southwest waters of the bay to the southeast waters of the bay.

$$
\mathrm{D}=\mathrm{A}-\mathrm{B}, \mathrm{E}=|\mathrm{A}-\mathrm{B}| / \max (\mathrm{A}, \mathrm{B})
$$

In the bottom waters from the southeast bay to the southwest bay, it is assumed that the matter content is a in the southeast and $b$ in the southwest.

Similarly, the absolutely horizontal loss amount of matter content is $\mathrm{d}>0$ and the relatively horizontal loss amount of matter content is from the southeast waters of the bay to the southwest waters of the bay. When $d<0$, it means that the absolutely horizontal loss amount of matter content is $-\mathrm{d}>0$ from the southwest waters of the bay to the southeast waters of the bay.

$$
\mathrm{d}=\mathrm{a}-\mathrm{b}, \mathrm{e}=|\mathrm{a}-\mathrm{b}| / \max (\mathrm{a}, \mathrm{b})
$$

\subsection{Formula for the Change of Vertical Matter Content}

In the waters from southeast to southwest of Jiaozhou Bay, it is assumed that the matter content in the surface waters of southeast bay is A, and that in the bottom waters of southeast bay is a. It is assumed that the investigation site there is site $n$, and the absolutely vertical diluted amount of matter content is $\mathrm{V}_{\mathrm{na}}>0$ and the relatively vertical diluted amount of matter content is $\mathrm{V}_{\text {nr. }}$. When $\mathrm{V}_{\mathrm{na}}<0$, the absolutely verticalsediment amount of matter content is $-\mathrm{V}_{\mathrm{na}}>0$, and the relatively vertical sediment amount of matter content is $\mathrm{V}_{\mathrm{nr}}$.

$$
\mathrm{Vna}=\mathrm{A}-\mathrm{a}, \mathrm{Vnr}=|\mathrm{A}-\mathrm{a}| / \max (\mathrm{A}, \mathrm{a})
$$

\subsection{Horizontal Loss Amount of Cd Content in the surface Layer and Bottom Layer}

It is assumed that from site 60 in southeast bay water area to site 54 in southwest bay water area simply refers to from A to $\mathrm{B}$, and the matter content is mainly $\mathrm{Cd}$ content.The horizontal loss amount of $\mathrm{Cd}$ content in the surface layer and bottom layer is revealed through the horizontal change of Cd content.

In August, in the surface waters from southeast bay to southwest bay, passing through the nearshore waters of the bay, the $\mathrm{Cd}$ content changed greatly [10], and the horizontal loss amount of Cd content is calculated by formula (1) (Table 1).

Table.1. Horizontal loss amount of $\mathrm{Cd}$ content in the surface layer

\begin{tabular}{|c|c|c|c|}
\hline from A to B & D & E & E \\
\hline August & 0.43 & 0.5733 & $57.33 \%$ \\
\hline
\end{tabular}

Meanwhile, in the bottom waters from southeast bay to southwest bay, passing through the nearshore waters of the bay, the $\mathrm{Cd}$ content in waters varied a lot [10], and the horizontal loss amount of $\mathrm{Cd}$ content is calculated by formula (2) (Table 2). 
Table.2. Horizontal loss amount of $\mathrm{Cd}$ content in the bottom layer

\begin{tabular}{|c|c|c|c|}
\hline from A to B & d & e & e \\
\hline August & 0.06 & 0.4285 & $42.85 \%$ \\
\hline
\end{tabular}

\subsection{Vertical Diluted and Sediment Amounts}

Matter content consists largely of $\mathrm{Cd}$ content. The vertical diluted and sediment amounts of $\mathrm{Cd}$ content in the surface layer and bottom layer were revealed through the vertical change of Cd content.

In August, in the waters from southeast to southwest of Jiaozhou Bay, the Cd content in the surface and bottom layers of the waters experienced major changes [11-13]. Through formula (3), the vertical diluted and sediment amounts of $\mathrm{Cd}$ content in the bottom layer were calculated (Table 3 ).

Table.3. Vertical diluted and sediment amounts of $\mathrm{Cd}$ in the surface layer and bottom layer

\begin{tabular}{|c|c|c|c|c|}
\hline Time & waters & Vna & Vnr & Vnr \\
\hline \multirow{2}{*}{ August } & $\begin{array}{c}\text { Southeastern waters of } \\
\text { bay }\end{array}$ & 0.61 & 0.8133 & $81.33 \%$ \\
\cline { 2 - 5 } & $\begin{array}{c}\text { Southwestern waters of } \\
\text { bay }\end{array}$ & 0.24 & 0.7500 & $75.00 \%$ \\
\hline
\end{tabular}

\section{Discussion}

\subsection{Changes of Cd Content Carried by Currents in the Bay}

Jiaozhou Bay is a shallow bay, which is generally dustpan-shaped and inclining straight, then inclining eastward in the bay mouth area.Its water is shallow in northwest and deep in southeast (Figure 3). In August, the main sea current carried high $\mathrm{Cd}$ content outside and passed through the bay mouth to the inside. Then the main sea current went along the northeast nearshore waters, to the most northeastern waters of the bay, reaching the estuary waters of Loushan River. After that, it turned to the west and passed through the coastal waters in the northern part of the bay. Afterwards, the current went to the westernmost waters in the northwest of the bay, reaching the estuary waters of Dagu River. And then it turned to the south, along the nearshore waters in the west of the bay, and reached the bay mouth waters (Figure 2).

So in August, the main sea current entered Jiaozhou Bay with a high Cd content of $1.11 \mu \mathrm{g} / \mathrm{L}$ and encircled the nearshore waters of the bay. It means that the main sea current in the bay waters passed through the southeast and southwest waters of the bay successively. According to the principle of vertical water body effect of matter, horizontal water body effect of matter and water body effect proposed by the authors [11-13], the horizontal change of matter content reveals the loss effect of horizontal water body, while the changes of matter content in the surface layer and bottom layer reveal the sediment effect and dilution effect of vertical water body. Therefore, the horizontal and vertical migration processes of $\mathrm{Cd}$ content in the waters from the southeast of bay to the southwest of bay was quantitatively studied through the horizontal and vertical matter content change models presented by the authors.

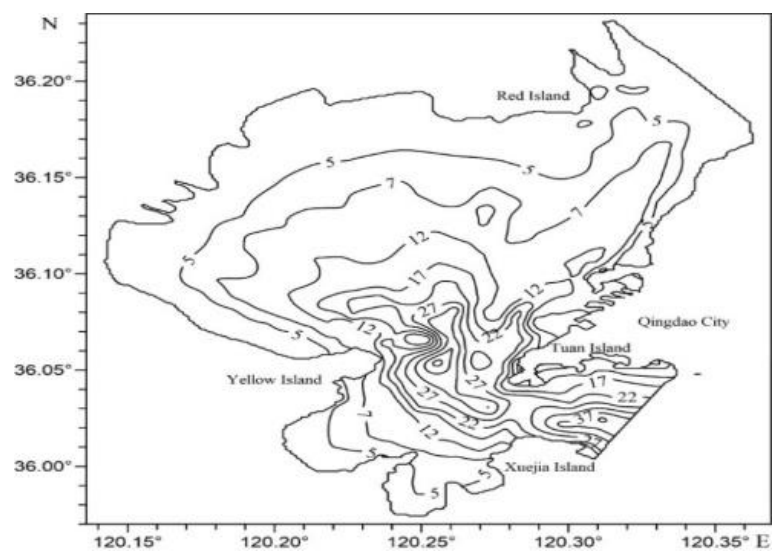

Figure.3. Water depth and topography of Jiaozhou Bay (m)

\subsection{Horizontal and Vertical Variation of CD Content}

On the spatial scale, in the surface waters in the southeast of JiaozhouBay in August, the Cd content transported by the main sea current was $1.11 \mu \mathrm{g} / \mathrm{L}$. In the waters of Jiaozhou Bay, the Cd content carried by the main sea current reached the southeast waters of the bay first, and the Cd content was $0.75 \mu \mathrm{g} / \mathrm{L}$. Under the action of tides and currents in the bay, the Cd content was decreasing along the gradient. After the main sea current encircled the nearshore waters of the bay, it reached the southwest waters of Jiaozhou Bay, and the Cd content was $0.32 \mu \mathrm{g} / \mathrm{L}$. From the southeast of the bay to the southwest of the bay, the Cd content decreased continuously, which indicated that there was almost no source of $\mathrm{Cd}$ content to provide $\mathrm{Cd}$ content for the nearshore currents in the movement of main sea current in the nearshore waters. In the coastal waters around the bay, the Cd content was transported by Dagu River only, which was low $0.96 \mu \mathrm{g} / \mathrm{L}$. Thus, in the movement of main sea current, if there is no source to provide the ocean current with high matter content, the matter content carried by the ocean current will decrease constantly.
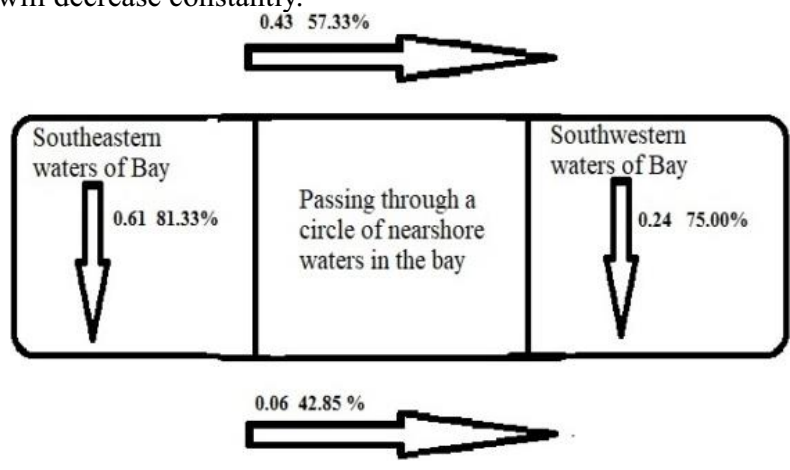

Figure.4. Model block diagram of horizontal and vertical changes of $\mathrm{Cd}$ content in August

According to the change model of horizontal matter content raised by the authors, the calculation results show that in August, the horizontal loss amount of $\mathrm{Cd}$ content in the surface layer reached high $57.33 \%$ from the southeast waters of the bay to the southwest waters of the bay. The horizontal loss amount of $\mathrm{Cd}$ bottom layer content also reached a relatively high $42.85 \%$ (Figure 4). The vertical diluted amount of Cd content in the surface layer and bottom layer was high $81.33 \%$ in the southeast bay waters and high $75.00 \%$ in the southwest bay waters (Figure 4).

Therefore, in the southeast and southwest waters of the bay in August, the absolutely horizontal loss amount of $\mathrm{Cd}$ content in the surface layer and bottom layer was $0.06-0.43 \mu \mathrm{g} / \mathrm{L}$, and the relatively horizontal loss amount of $\mathrm{Cd}$ content in the surface layer and bottom layer was $42.85-57.33 \%$. The absolutely vertical diluted amount of $\mathrm{Cd}$ content in the surface 
layer and bottom layer was $0.24-0.61 \mu \mathrm{g} / \mathrm{L}$, and the relatively vertical diluted amount was $75.00-81.33 \%$.

\subsection{Horizontal Loss Amount}

In August, the horizontal loss amount of $\mathrm{Cd}$ content in the surface layer reached a relatively high $57.33 \%$ (Table 1) when the ocean current passed through a circle of the coastal waters in the bay from southeast of the bay to the southwest of the bay. Itshows that there was almost no source of $\mathrm{Cd}$ content. Accordingly, in the horizontal migration process of $\mathrm{Cd}$ content in the surface layer, almost half of $\mathrm{Cd}$ content in the surface layer was lost.And with the movement of ocean current, $\mathrm{Cd}$ content in it was greatly lost. As a result, the $\mathrm{Cd}$ content in the surface layer of the ocean current in the southeast of the bay was $0.75 \mu \mathrm{g} / \mathrm{L}$; and when it reached the southwest of the bay, the $\mathrm{Cd}$ content in the surface layer decreased to $0.32 \mu \mathrm{g} / \mathrm{L}$.

Simultaneously, the horizontal loss amount of $\mathrm{Cd}$ bottom layer content reached a relatively high $42.85 \%$ (Table 2 ) when the ocean current passed through a circle of the coastal waters in the bay from the southeast of the bay to the southwest of the bay. It indicates that the $\mathrm{Cd}$ content in the bottom layer from the southeast of the bay to the southwest of the bay sank to the sea floor and was buried there. Hence in the process of horizontal migration of $\mathrm{Cd}$ content in the bottom layer, a great deal of loss of $\mathrm{Cd}$ content in the bottom layer was caused after a long journey. The Cd content in the bottom layer was $0.14 \mu \mathrm{g} / \mathrm{L}$ in the waters in the southeast of the bay, and decreased to $0.08 \mu \mathrm{g} / \mathrm{L}$ when the ocean current reached the waters in the southwest of the bay.

So in the process of horizontal migration, in the surface waters in August, the main sea current carried $\mathrm{Cd}$ content through a circle ofthe nearshore waters in the bay, with almost no source of $\mathrm{Cd}$ content. Therefore, in the horizontal migration process of $\mathrm{Cd}$ content in the surface layer, after a long journey, the $\mathrm{Cd}$ content in the surface layer and the bottom layer was greatly lost, with the absolutely horizontal loss amount of 0.06 $0.43 \mu \mathrm{g} / \mathrm{L}$ and the relatively horizontal loss amount of 42.85-57.33\%.

\subsection{Vertical Loss Amount}

In Jiaozhou Bay in August, the Cd content transported by the main sea current was $1.11 \mu \mathrm{g} / \mathrm{L}$. The main sea current first came into the surface waters of the southeast bay, and then passed through a circle of the nearshore waters in the bay to the waters of the southwest bay. In the southeast waters of the bay, the vertical diluted amount of $\mathrm{Cd}$ content in the surface and bottom layers was $81.33 \%$. It shows that the high $\mathrm{Cd}$ content transported by the main sea current reached the southeast waters of the bay first. And the high Cd content on the surface could rapidly and continuously settle to the seabed, where a high sediment and diluted amounts of $81.33 \%$ were obtained. In this way, the Cd content in the water body of the southeast bay had a high value of $0.75 \mu \mathrm{g} / \mathrm{L}$ and a high sediment amount.

Then, the main sea current passed through a circle of the nearshore waters in the bay and reached the waters in the southwest of the bay. In the southwest waters of the bay, the vertical diluted amount of $\mathrm{Cd}$ content in the surface and bottom layers reached high $75.00 \%$. It indicates that the high $\mathrm{Cd}$ content in the surface layer could rapidly and continuously settle to the seabed when the high Cd content transported by the main sea current passed through the nearshore waters in the bay. Therefore, the Cd content decreased from the high value of $0.75 \mu \mathrm{g} / \mathrm{L}$ in the southeast bay to the low value of $0.32 \mu \mathrm{g} / \mathrm{L}$ in the southwest bay. In the southwest waters of Jiaozhou Bay, although the Cd content in the surface has reached a low value, high sediment and diluted amounts of $75.00 \%$ were obtained at the seabed. In this way, the $\mathrm{Cd}$ content in the water body of southwest bay had a low value of $0.32 \mu \mathrm{g} / \mathrm{L}$ and a high sediment amount.

Therefore, in the process of vertical migration in August, the $\mathrm{Cd}$ content transported by the main sea current was relatively high in the southeast waters of the bay, and the vertical diluted amount of $\mathrm{Cd}$ content in the surface and bottom layers was as high as $81.33 \%$. Although it was relatively low in the southwest waters of the bay, the vertical diluted amount of $\mathrm{Cd}$ content in the surface and bottom layers was high $75.00 \%$. Accordingly, the main sea current reached the waters of the southwest bay from the waters of the southeast bay through a circle of the nearshore waters in the bay, and the vertical diluted amount of $\mathrm{Cd}$ content in the surface and bottom layers kept high.

\section{Conclusion}

According to the horizontal and vertical change models of $\mathrm{Cd}$ content proposed by the authors, the horizontal loss amount and vertical diluted amount of $\mathrm{Cd}$ content in the surface and bottom layers were calculated, and the model block diagram of horizontal and vertical changes of $\mathrm{CD}$ content was determined.

In August, the absolutely horizontal loss amount of $\mathrm{Cd}$ content in the surface layer and bottom layer was 0.06$0.43 \mu \mathrm{g} / \mathrm{L}$, and the relatively horizontal loss amount of $\mathrm{Cd}$ content in the surface layer and bottom layer was $42.85-57.33 \%$. In the southeast and southwest waters of the bay, the absolutely vertical diluted amount of $\mathrm{Cd}$ content in the surface and bottom layers was $0.24-0.61 \mu \mathrm{g} / \mathrm{L}$, and the relatively vertical diluted amount was $75.00-81.33 \%$.

In the process of horizontal migration in the surface waters in August, the main sea current carried Cd content through a circle of the nearshore waters in the bay, and there was almost no source of $\mathrm{Cd}$ content. Thus, in the horizontal migration process of $\mathrm{Cd}$ content in the surface layer, after a long journey, the $\mathrm{Cd}$ content in the surface layer and the bottom layer was greatly lost, with the absolutely horizontal loss amount of $0.06-$ $0.43 \mu \mathrm{g} / \mathrm{L}$ and the relatively horizontal loss amount of $42.85-57.33 \%$. It reveals that the main sea current transported high content of $\mathrm{Cd}$ into Jiaozhou Bay, and the $\mathrm{Cd}$ content was decreasing with the continuous movement of the current. When the current leftJiaozhou Bay, the Cd content carried by the current becomes low if there is no source to provide Cd content for the current in the process of current movement. It proves Dongfang Yang's migration law of matter content put forward by the authors: the longer the migration route of matter content, the greater the loss amount of matter content in the route. If the matter content comes from the same starting point and reaches the same end point, and the value of the content at the starting point is fixed, then the longer the way the matter content goes, the lower the value of the matter content at the end point.

In the process of vertical migration in August, the $\mathrm{Cd}$ content transported by the main sea current was high in the southeast waters of the bay, and the vertical dilutedamount of $\mathrm{Cd}$ content in the surface and bottom layers was $81.33 \%$. The main sea current reached the waters of the southwest bay from the waters of the southeast bay through a circle of the nearshore waters in the bay. At this time, the Cd content transported by the main sea current was relatively low in the waters of the southwest bay, but the vertical diluted amount of the $\mathrm{Cd}$ content in the surface and bottom layers was still very high $75.00 \%$,revealing that the vertical diluted amount of $\mathrm{Cd}$ content in the surface layer and bottom layer was very high in any water area, whether the Cd content was high or low.

\section{References}

1. Dongfang Yang, Sixi Zhu, Fengyou Wang, Huazhong He and Yunjie Wu. The distribution and content of Cadmium in Jiaozhou 
Bay [J]. Applied Mechanics and Materials Vols.644-650. 2014, 5325-5328.

2. Dongfang Yang, Sixi Zhu, Xiuqin Yang, Xiaoli Zhao and Fengyou Wang. Pollution level and Sources of $\mathrm{Cd}$ in Jiaozhou Bay [J]. Materials Engineering and Information Technology Apllication. 2015, 558-561.

3. Dongfang Yang, Fengyou Wang, Xiuqin Yang, Ming Wang, Sixi Zhu. Cadmium background pollution in Jiaozhou Bay [J]. Advances in Engineering Research. 2016, 60: 1347-1350.

4. Dongfang Yang, Sixi Zhu, Zhikang Wang, Xiuqin Yang, Fengyou Wang. Spatial-temporal changes of $\mathrm{Cd}$ in Jiaozhou Bay [J]. Computer Life, 2016, 4(5): 446-450.

5. Dongfang Yang, Fengyou Wang, Sixi Zhu, ChunhuaSu and Xiuqin Yang. The influence of river on Cd contents in Jiaozhou Bay [J]. World Scientific Research Journal, 2017, 3(1): 1-5.

6. Dongfang Yang, Haixia Li,Xiaolong Zhang, Qi Wang, Zhenqing Miao. Spatial-temporal migration laws of Cd in Jiaozhou Bay [J]. Earth and Environment Science, 2018, 113 (012129): 1-4.

7. YANG D F, CHEN Y, GAO Z H, et al. SiLicon Limitation on primary production and its destiny in Jiaozhou Bay, China IV transect offshore the coast with estuaries $[\mathrm{J}]$. Chin. J. OceanoL. LimnoL. 2005, 23(1): 72-90.

8. Dongfang Yang, Fan Wang, Zhenhui Gao, et al. Ecological Phenomena of Phytoplankton in Jiaozhou Bay [J]. Marine Science, 2004, 28 (6): 71-74.

9. State Oceanic Administration. The Specification for Marine Monitoring [Z]. Beijing: China Ocean Press, 1991.

10. Dongfang Yang, Zhenqing Miao, Huanzhi Xu, Yu Chen, Jingya Sun. Jiaozhou Bay water exchange time [J]. Marine Environmental Science, 2013, 32 (3): 373-380.

11. Dongfang Yang, Fengyou Wang, Huozhong He, Sixi Zhu and Yunjie Wu. Vertical water body effect of benzene hexachloride $[\mathrm{J}]$. Proceedings of the 2015 international symposium on computers and informatics. 2015, 2655-2660.

12. Dongfang Yang, Fengyou Wang, Xiaoli Zhao, Yunjie Wu, Six Zhu. Horizontal waterbody effect of hexachlorocyclohexane [J]. Sustainable Energy and Environment Protection. 2015, 191-195.

13. Dongfang Yang, Fengyou Wang, Xiuqin Yang, Yunjie $\mathrm{Wu}$ and Sixi Zhu. Water's effect of benzene hexachloride [J]. Advances in Computer Science Research. 2015, 2352: 198-204. 